\title{
Efficacy and safety of Ginkgo biloba extract as an "add-on" treatment to metformin for patients with metabolic syndrome: a pilot clinical study
}

This article was published in the following Dove Press journal:

Therapeutics and Clinical Risk Management

\author{
Tavga Ahmed Aziz' \\ Saad Abdulrahman Hussain ${ }^{2}$ \\ Taha Othman $\mathrm{Mahwi}^{3}$ \\ Zheen Aorahman Ahmed' \\ 'Department of Pharmacology and \\ Toxicology, College of Pharmacy, \\ University of Sulaimani, Kurdistan, \\ Iraq; ${ }^{2}$ Department of Pharmacology \\ and Toxicology, Faculty of Pharmacy, \\ Al-Rafidain University College, \\ Baghdad, Iraq; ${ }^{3}$ Department of Internal \\ Medicine, College of Medicine, \\ University of Sulaimani, Kurdistan, Iraq
}

Correspondence: Saad Abdulrahman Hussain

Department of Pharmacology and Toxicology, Faculty of Pharmacy, Al-Rafidain University College, 10052 Al-Mustansiriya St. 75, Baghdad, Iraq Tel +964 790 I 712624

Email saad.hussain@coalrafidain.edu.iq
Background and aim: Ginkgo biloba $(\mathrm{GKB})$ extract has shown to be beneficial in experimental models of metabolic and inflammatory disorders such as diabetes and metabolic syndrome (MTS). The objective of this pilot clinical study was to evaluate the effects of GKB extract as an "add-on" treatment with metformin (Met) in MTS patients.

Patients and methods: We performed a randomized, placebo-controlled, double-blinded clinical study in subjects with MTS. Forty patients completed the 90-day clinical trial and were randomly allocated to administer either GKB extract (120 mg capsule/day) or placebo (120 mg starch/day) as an add-on treatment with their currently used doses of Met for 90 days. During the study, body mass index (BMI), waist circumference (WC), serum leptin, glycated hemoglobin (HbA1c), fasting serum glucose (FSG), insulin, insulin resistance (IR), visceral adiposity index (VAI), lipid profile, and the inflammatory markers high sensitive C-reactive protein (hsCRP), tumor necrosis factor- $\alpha$ (TNF- $\alpha$ ), and interleukin-6 (IL-6) were evaluated.

Results: GKB extract significantly decreases HbA1c, FSG and insulin levels, IR, BMI, WC, VAI, serum leptin, and the inflammatory markers compared to baseline values. Simultaneously, GKB did not negatively affect the functions of the liver, kidney, and hematopoietic system.

Conclusion: The use of GKB extract as an adjuvant with Met was effective in improving the outcome of patients with MTS.

Keywords: Ginkgo biloba, metabolic syndrome, metformin, adiposity, insulin resistance, inflammation

\section{Introduction}

Metabolic syndrome (MTS) is defined as a clustering of different metabolic disturbances such as glucose intolerance, dyslipidemia, abdominal obesity, and hypertension, with increased incidence in various communities worldwide. ${ }^{1}$ Although the pathogenesis of MTS is multifactorial and inadequately defined, chronic inflammation and insulin resistance (IR) are well characterized and potentially involved. ${ }^{2,3}$ During the course of MTS, the disturbed adipose tissue functions predisposes to excessive production of many proinflammatory cytokines such as interleukin-1 $\beta$ (IL-1 $\beta$ ), interleukin-6 (IL-6), and tumor necrosis factor- $\alpha(\mathrm{TNF}-\alpha)$ and mostly associated with the exaggerated state of oxidative stress. ${ }^{4}$ This systematically initiated inflammatory events that may increase the risk of developing cardiovascular disorders. ${ }^{5}$ Despite the availability of many treatment approaches for MTS, it remains a hard public health concern. Currently, there are many pharmacological options available to manage the disorders associated with MTS, including metformin (Met) and other insulin sensitizers; however, their chronic use may be accompanied with various adverse effects such as lactic acidosis and vitamin 
$\mathrm{B}_{12}$ deficiency. ${ }^{6}$ The use of plant-derived pharmacologically active agents as nutraceuticals has been dramatically accepted in clinical practice over the past few decades. Accordingly, there is a need for new pharmacologically active agents, based on medicinal plants, for the treatment of MTS-associated disorders, with Ginkgo biloba L. (GKB) extract being a potential alternative. GKB leaves' extracts are commonly used since ancient times as dietary supplements ${ }^{7}$ and found effective to improve cognitive functions and enhancement of memory in patients with central nervous system disorders including Alzheimer's disease. ${ }^{8}$ These claims are not supported by strong evidence from randomized clinical trials. The total GKB extract contains various biologically active components, including terpene trilactones and flavonols, ${ }^{9}$ and the therapeutic benefits are thought to be the combined effects of the whole components of the extract. ${ }^{10}$ The standardized GKB leaf extract, EGb 761, is widely prescribed in many countries as an adjuvant in the treatment of arteriosclerosis, thrombus formation, ischemic heart disease, dementia, and the prevention of diabetes mellitus. ${ }^{11,12}$ The contents of the extract also have antioxidant activities and act as free radical scavengers. ${ }^{13,14}$ Moreover, GKB extract has been proved to decrease diastolic pressure in patients with essential hypertension ${ }^{15}$ and improve visual function in patients with normal tension glaucoma. ${ }^{16}$ Dietary supplements containing GKB extract are found to be safe and only produce minor adverse effects such as headache, constipation, stomach upset, dizziness, and a mild allergic response. ${ }^{17}$ Collectively, the previous findings highly suggest that GKB extract may be an effective choice for the management of metabolic disorders in MTS. In the present study, we evaluated the efficacy and safety of standardized GKB extract, as an add-on treatment to Met in patients with MTS.

\section{Patients and methods Study design}

We performed a prospective, randomized, double-blinded placebo controlled pilot clinical study between December 2016 and October 2017 at the Center of Diabetes and Endocrinology, Directory of Health, Sulaimani. The enrolled patients were randomly allocated (2:2 bases) to the Met + placebo treatment group (control group) and the Met + GKB group. The Met + GKB group received $120 \mathrm{mg}$ /day GKB extract (EGb 761; Apollo Healthcare Resources, West Coast Vista, Singapore) capsules once daily in addition to their currently used Met (Merck Santé SAS, Lyon, France), while the Met + placebo group received $120 \mathrm{mg}$ /day placebo formula with Met doses. Both the patients and the evaluators were unaware of the treatment assignment. The study protocol was approved by the Clinical Research Ethics Committee of the College of Medicine, University of Sulaimani (certificate no 507/1024), in accordance with the Declaration of Helsinki revised in 2000.

\section{Participants}

Ninety patients with MTS were initially screened for eligibility. Only sixty patients were included in the study. Patients were enrolled when they fulfill the diagnostic criteria for MTS according to the International Diabetes Federation (IDF), American Heart Association/National Heart, Lung, and Blood Institute (AHA/NHLBI), and the International Atherosclerosis Society definitions (elevated waist circumference $[\mathrm{WC}] \geq 80 \mathrm{~cm}$; elevated TG $\geq 150 \mathrm{mg} / \mathrm{dL}$; reduced highdensity lipoprotein cholesterol [HDL-c] $<40 \mathrm{mg} / \mathrm{dL}$; elevated blood pressure systolic $\geq 130$ and/or diastolic $\geq 85 \mathrm{mmHg}$, and elevated fasting glucose $\geq 100 \mathrm{mg} / \mathrm{dL}$ ). ${ }^{18}$ According to the inclusion criteria, patients of both sex with an age range of 25-65 years, diagnosed as having MTS for not $<1$ year and their glycemic status was uncontrolled by the prescribed dose of Met therapy alone. The exclusion criteria include patients with type 1 diabetes mellitus (T1DM), pregnancy, ischemic heart disease, cardiac arrhythmias, glucose-6-phosphate dehydrogenase (G6PD) deficiency, bleeding disorders, seizures, and known hypersensitivity to any component of the trial drugs (GKB extract, Met, or placebo). Moreover, patients on supplements that contain multivitamins and polyphenols were also excluded. All patients declare their acceptance to participate in the study and signed informed consent. Only 40 patients completed the 90 -day treatment program (Figure 1), and their data were presented in the study.

\section{Intervention}

We designed a 90-day treatment protocol in which each patient in the Met + GKB group (30 patients) administered orally $120 \mathrm{mg} /$ day of GKB extract as add-on drug to the currently used Met dose (Table 1), while each patient in the Met + placebo group (30 patients) administered $120 \mathrm{mg}$ /day of a placebo formula with the Met dose. The enrolled patients were advised to visit the Diabetes Center on 2-week bases for clinical assessment and to receive the drug doses enough for the next 2 weeks to ensure compliance with the study protocol. During treatment follow-up period, the patients were advised not to use medications that interfere with the study protocol. Moreover, they were also advised to maintain their lifestyle, exercise, and restricted dietary habits that they followed during their daily lives. 


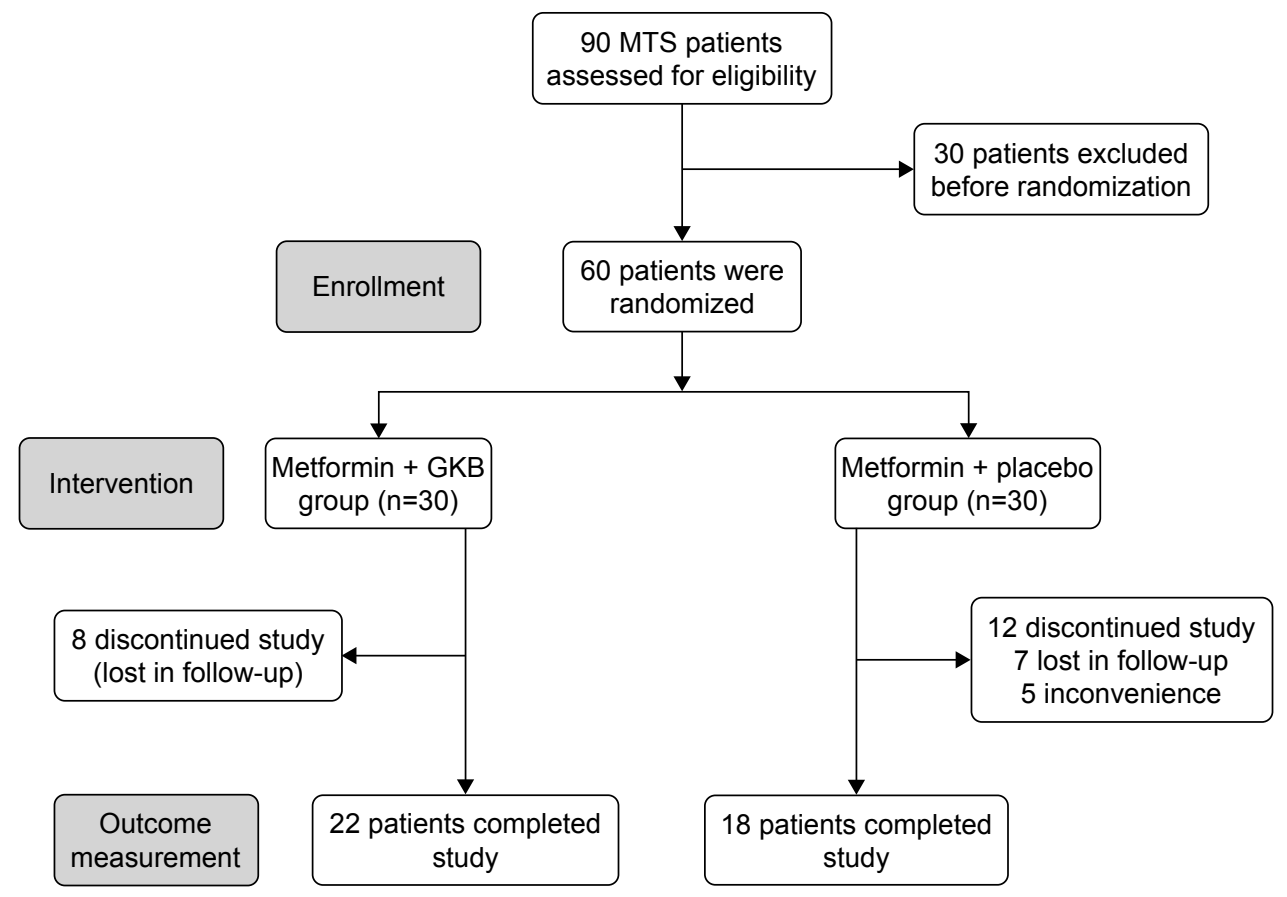

Figure I Flowchart displaying the participant's screening, randomization, and treatment. Abbreviations: MTS, metabolic syndrome; GKB, Ginkgo biloba.

\section{Anthropometric outcomes}

Anthropometric measures were evaluated by two assistants at baseline and after 90 days at the end of the treatment. Height and weight were measured by an electronic scale and

Table I Baseline characteristics of the randomly allocated MTS patients

\begin{tabular}{|c|c|c|c|}
\hline Parameters & $\begin{array}{l}\text { Met + placebo } \\
(n=18)\end{array}$ & $\begin{array}{l}\text { Met }+ \text { GKB } \\
(n=22)\end{array}$ & $P$-value \\
\hline Age (years) & $47.3 \pm 10.8$ & $50.7 \pm 7.8$ & 0.25 \\
\hline Male, n (\%) & $2(1 I)$ & $6(27)$ & 0.54 \\
\hline Weight (kg) & $79.8 \pm 14.6$ & $88.5 \pm 14.6$ & 0.07 \\
\hline BMI $\left(\mathrm{kg} / \mathrm{m}^{2}\right)$ & $34.2 \pm 5.6$ & $36.3 \pm 4.9$ & 0.22 \\
\hline WC (cm) & $102.7 \pm 7.6$ & $109.9 \pm 8.0$ & 0.07 \\
\hline VAl & $203.8 \pm 59.4$ & $237.7 \pm 81.2$ & 0.15 \\
\hline Insulin resistance & $|5| \pm 2.5$. & $16.7 \pm 4.1$ & 0.16 \\
\hline MTS duration (years) & $3.8 \pm 2.1$ & $3.3 \pm 2.0$ & 0.35 \\
\hline \multicolumn{4}{|l|}{ Metformin therapy } \\
\hline Duration of use (months) & $40.1 \pm 30.7$ & $30.6 \pm 22.7$ & 0.27 \\
\hline Daily dose (g) & $1.1 \pm 0.5$ & $\mathrm{I} .3 \pm 0.3$ & 0.37 \\
\hline \multicolumn{4}{|l|}{ Biochemical markers } \\
\hline $\mathrm{HbAlc} \mathrm{( \% )}$ & $7.2 \pm 0.8$ & $7.5 \pm 0.8$ & $0.4 \mathrm{I}$ \\
\hline FSG (mg/dL) & $130.9 \pm 24.3$ & $147.0 \pm 24.2$ & 0.05 \\
\hline Serum insulin $(\mu \mathrm{U} / \mathrm{mL})$ & $22.9 \pm 12.2$ & $21.2 \pm 8.2$ & $0.6 \mathrm{I}$ \\
\hline $\mathrm{TG}(\mathrm{mg} / \mathrm{dL})$ & $157.3 \pm 87.1$ & $175.3 \pm 85.3$ & 0.39 \\
\hline $\mathrm{TC}(\mathrm{mg} / \mathrm{dL})$ & $185.7 \pm 53.2$ & $182.7 \pm 34.2$ & 0.83 \\
\hline $\mathrm{HDL}(\mathrm{mg} / \mathrm{dL})$ & $41.8 \pm 6.5$ & $39.8 \pm 6.3$ & 0.33 \\
\hline LDL (mg/dL) & $139.1 \pm 32.2$ & $144.5 \pm 29.2$ & 0.58 \\
\hline
\end{tabular}

Notes: Values are mean \pm SD. GKB: $120 \mathrm{mg}$ GKB extract.

Abbreviations: BMI, body mass index; FSG, fasting blood glucose; GKB, Ginkgo biloba; HbA I c, glycated hemoglobin; HDL, high-density lipoprotein; LDL, low-density lipoprotein; Met, metformin; MTS, metabolic syndrome; TC, total cholesterol; TG, triglyceride; VAI, visceral adiposity index; WC, waist circumference. a wall-mounted stadiometer. WC was measured by a tape measure. Each measurement was taken twice, and the average values were recorded. In addition, the body mass index (BMI) and visceral adiposity index (VAI) were calculated according to the following formula: BMI = weight $(\mathrm{kg}) /$ height $^{2}\left(\mathrm{~m}^{2}\right)$, female VAI $=(\mathrm{WC} / 36.58+[1.89 \times \mathrm{BMI}]) \times(\mathrm{TG} / 0.81) \times$ (1.52/high-density lipoprotein [HDL]), male VAI = $(\mathrm{WC} / 39.68+[1.88 \times \mathrm{BMI}]) \times(\mathrm{TG} / 1.03) \times(1.31 / \mathrm{HDL}) .{ }^{19}$

\section{Biochemical and hematological tests}

After $12 \mathrm{~h}$ fasting, a blood sample was obtained by venipuncture from each patient at baseline and after initiation of the 90-day treatment with GKB extract. Approximately $2.0 \mathrm{~mL}$ of the blood was drawn into ethylenediaminetetraacetic acid tubes and used for the determination of glycated hemoglobin (HbA1c) using a ready-made kit (Hoffman-La Roche Ltd., Basel, Switzerland) according to the manufacturer's instructions; meanwhile, hemoglobin $(\mathrm{Hb})$ content, hematocrit, red blood cell, white blood cell, and platelet counts were measured using the hematology analyzer (Spincell 3; Spinreact SAU, Girona, Spain). The remaining blood $(8.0 \mathrm{~mL})$ was kept into plain tubes and allowed to clot before centrifuging at $300 \times g$ for $20 \mathrm{~min}$ to obtain the serum. The serum was either analyzed immediately or kept frozen at $-20^{\circ} \mathrm{C}$ for later use. The fasting serum glucose (FSG), lipid profile (triglyceride [TG], total cholesterol [TC], low-density lipoprotein cholesterol [LDL-c], and HDL-c), urea and creatinine levels, and the liver function 
indicators aspartate transaminase, alanine aminotransferase, and alkaline phosphatase activities were determined colorimetrically using ready-made kits (Randox, London, UK) according to the manufacturer's instructions. The serum insulin content was measured using an immunoassay method (Roche-Cobas e 411; Hoffman-La Roche Ltd.). Moreover, the changes from baseline in the serum concentrations of the inflammatory markers high sensitive C-reactive protein (hsCRP), IL-6, and TNF- $\alpha$ were evaluated using an enzymelinked immunosorbent assay kit (Elabscience, Houston, TX, USA) according to the manufacturer's instructions.

\section{Statistical analysis}

The statistical analysis was performed using the GraphPad Prism 5.1 software (GraphPad Software, Inc., La Jolla, CA, USA). Descriptive statistics was utilized to compare the patient's characteristics between the two groups. Paired $t$-test was utilized to evaluate the difference between pretreatment mean and post-treatment mean of the same group. Unpaired $t$-test was utilized to evaluate the differences between posttreatment mean of the different groups. Two-way analysis of variance, supported by Bonferroni's post hoc analysis, and analysis of covariance were used to determine the difference between mean of independent samples at $P$-value $<0.05$.

\section{Results}

The baseline characteristics for the enrolled MTS patients are shown in Table 1. There were no significant differences $(P>0.05)$ between the parameters between the groups. Adjunct treatment with GKB extract with Met was well tolerated, and none of the included patients had adverse effects that necessitate withdrawal from the study. No safety parameters (liver, kidney, and hematopoietic functions) changed significantly during the treatment period compared with placebo. Glycemic status measurements revealed a significant decrease $(P=0.002)$ in the FSG levels following 90 days of adjuvant GKB extract use with Met compared to the levels observed at baseline (Table 2). Moreover, a highly significant $(P=0.001)$ decrease in HbA1c was observed following 90 days of GKB extract supplementation as add-on treatment with Met (Table 2). Furthermore, reductions in insulin concentration were significantly greater in the GKB-treated group than in the placebo group $(P<0.001)$. Additionally, the decrease in IR between groups was significantly different $(P=0.003)$ (Table 2$)$. Table 3 demonstrates the changes in body weight and adiposity markers of MTS patients, where treatment with GKB extract and Met decreased the BMI significantly $(P<0.001)$
Table 2 Glycemic control markers of metabolic syndrome patients maintained on Met and treated with GKB extract

\begin{tabular}{|c|c|c|c|c|}
\hline \multirow[t]{2}{*}{ Parameters } & \multicolumn{2}{|c|}{$\begin{array}{l}\text { Met + placebo } \\
(n=18)\end{array}$} & \multicolumn{2}{|l|}{$\begin{array}{l}\text { Met }+ \text { GKB } \\
(n=22)\end{array}$} \\
\hline & Baseline & 90 days & Baseline & 90 days \\
\hline FSG (mg/dL) & $130.9 \pm 24.3$ & $147.7 \pm 45.8$ & $147.0 \pm 24.2$ & $129.1 \pm 16.1 *$ \\
\hline $\mathrm{HbAlc}(\%)$ & $7.2 \pm 0.8$ & $7.4 \pm 0.7$ & $7.5 \pm 0.8$ & $6.9 \pm 0.7^{*}$ \\
\hline $\begin{array}{l}\text { Serum insulin } \\
(\mu \mathrm{U} / \mathrm{mL})\end{array}$ & $22.9 \pm 27.0^{\mathrm{a}}$ & $22.4 \pm 9.7^{\mathrm{a}}$ & $21.2 \pm 8.2^{\mathrm{a}}$ & II. $8 \pm 5.4^{*, \mathrm{~b}}$ \\
\hline Insulin resistance & $15.1 \pm 2.5^{\mathrm{a}}$ & $17.5 \pm 4.8^{*, \mathrm{~b}}$ & $16.7 \pm 4.1^{\mathrm{a}}$ & $13.6 \pm 2.9^{*, c}$ \\
\hline
\end{tabular}

Notes: Values were mean \pm SD. Values with nonidentical superscripts (a, b, and c) among groups were significantly different (ANOVA, $P<0.05$ ). GKB, $120 \mathrm{mg}$ GKB extract. *Significantly different from baseline in each group (paired $t$-test, $P<0.05$ ). Abbreviations: FSG, fasting serum glucose; GKB, Ginkgo biloba; HbAlc, glycated hemoglobin; ANOVA, analysis of variance; Met, metformin.

after 90 days compared with baseline value (33.9 \pm 5.1 vs $36.3 \pm 4.9 \mathrm{~kg} / \mathrm{m}^{2}$ ). Meanwhile, BMI value of the placebo group was not significantly modified after 90 days of treatment $(P=0.07)$. Moreover, GKB-treated patients showed significantly lower $(P<0.001) \mathrm{WC}$ after 90 days compared with baseline $(106.7 \pm 7.0$ vs $109.9 \pm 8.0 \mathrm{~cm})$. Meanwhile, WC was significantly increased after 90 days in patients treated with placebo and Met compared to the baseline value (105.1 \pm 8.4 vs $102.7 \pm 7.6 ; P=0.008)$. Regarding the effect of GKB treatment on the VAI, it was significantly decreased after 90 days compared with baseline value (182.6 \pm 74.7 vs $237.7 \pm 81.2 ; P=0.002)$, while no significant changes reported in the placebo group at the end of treatment (210.8 \pm 48.6 vs baseline 203.8 $\pm 59.4 ; P=0.5$ ). Additionally, the influence of GKB, as add-on treatment with Met, on serum leptin levels is demonstrated in Table 3. The GKB extract significantly decreased serum leptin levels after 90 days compared with baseline value $(4.7 \pm 0.6$ vs $8.3 \pm 1.1 \mathrm{ng} / \mathrm{mL} ; P<0.001)$, and this change was found to be significantly different $(P<0.001)$ from that of the placebo group at the end of the period of treatment. Serum leptin levels in the placebo group did not

Table 3 Changes in body weight and adiposity markers of metabolic syndrome patients maintained on Met and treated with GKB extract

\begin{tabular}{|c|c|c|c|c|}
\hline \multirow[t]{2}{*}{ Parameters } & \multicolumn{2}{|c|}{$\begin{array}{l}\text { Met + placebo } \\
(n=18)\end{array}$} & \multicolumn{2}{|l|}{$\begin{array}{l}\text { Met }+ \text { GKB } \\
(n=22)\end{array}$} \\
\hline & Baseline & 90 days & Baseline & 90 days \\
\hline BMI $\left(\mathrm{kg} / \mathrm{m}^{2}\right)$ & $34.2 \pm 5.6$ & $33.7 \pm 5.7$ & $36.3 \pm 4.9$ & $33.9 \pm 5.1 *$ \\
\hline$W C(\mathrm{~cm})$ & $102.7 \pm 7.6$ & $105.1 \pm 8.4^{*}$ & $109.9 \pm 8.0$ & $106.7 \pm 7.0^{*}$ \\
\hline VAI & $203.8 \pm 59.4$ & $210.8 \pm 48.6$ & $237.7 \pm 81.2$ & $182.6 \pm 74.7^{*}$ \\
\hline Serum leptin (ng/mL) & $7.9 \pm 1.7^{\mathrm{a}}$ & $6.7 \pm 2.1^{a}$ & $8.3 \pm 1.1^{\mathrm{a}}$ & $4.7 \pm 0.6 *, b$ \\
\hline
\end{tabular}

Notes: Values are mean \pm SD. GKB, $120 \mathrm{mg}$ GKB extract. Values with nonidentical superscripts ( $a$ and $b$ ) among groups are significantly different (ANOVA, $P<0.05$ ). *Significantly different from baseline in each group (paired $t$-test, $P<0.05$ ).

Abbreviations: ANOVA, analysis of variance; BMI, body mass index; GKB, Ginkgo biloba; Met, metformin; VAI, visceral adiposity index; WC, waist circumference. 
Table 4 Changes in the lipid profile of metabolic syndrome patients maintained on Met and treated with GKB extract

\begin{tabular}{|c|c|c|c|c|}
\hline \multirow[t]{2}{*}{ Parameters } & \multicolumn{2}{|c|}{$\begin{array}{l}\text { Met + placebo } \\
(n=18)\end{array}$} & \multicolumn{2}{|c|}{$\begin{array}{l}\text { Met + GKB } \\
(n=22)\end{array}$} \\
\hline & Baseline & 90 days & Baseline & 90 days \\
\hline $\mathrm{TG}(\mathrm{mg} / \mathrm{dL})$ & $151.3 \pm 87.1$ & $159.9 \pm 67.6$ & $175.3 \pm 85.3$ & $161.9 \pm 73.5$ \\
\hline TC (mg/dL) & $185.7 \pm 53.2$ & $193.7 \pm 36.6$ & $182.7 \pm 34.2$ & $167.8 \pm 31.6 *$ \\
\hline LDL (mg/dL) & $139.1 \pm 32.2$ & $143.9 \pm 32.1$ & $144.5 \pm 29.2$ & $128.0 \pm 28.6^{*}$ \\
\hline $\mathrm{HDL}(\mathrm{mg} / \mathrm{dL})$ & $41.8 \pm 6.5$ & $41.3 \pm 5.7$ & $39.8 \pm 6.3$ & $46.5 \pm 8.9 *$ \\
\hline
\end{tabular}

Notes: Values are mean \pm SD. GKB, $120 \mathrm{mg}$ GKB extract. *Significantly different from baseline in each group (paired $t$-test, $P<0.05$ ).

Abbreviations: GKB, Ginkgo biloba; HDL, high-density lipoprotein; LDL, lowdensity lipoprotein; Met, metformin; TC, total cholesterol; TG, triglyceride.

change significantly after 90 days of treatment $(6.7 \pm 2.1 \mathrm{vs}$ $7.9 \pm 1.7 \mathrm{ng} / \mathrm{mL} ; P=0.51)$. The main reported changes in the lipid profile during the trial following treatment with GKB extract are shown in Table 4. In the GKB-treated group, compared with the baseline level, we reported a significant decrease in TC $(167.8 \pm 31.6$ vs $182.7 \pm 34.2, P=0.01)$, LDL-c (128.0 \pm 28.6 vs $144.5 \pm 29.2, P=0.02)$, and HDL-c (46.5 \pm 8.9 vs $39.8 \pm 6.3, P<0.001)$, while no significant changes $(P>0.05)$ were reported in TG levels. In the placebo-treated group, compared with the baseline level, we did not report significant changes in lipid profile. In comparing the adjuvant use of GKB extract with that of placebo with Met on the lipid profile, they did not demonstrate significant differences at the end of the treatment, even when GKB produced significant changes. Serum concentrations of hsCRP, TNF- $\alpha$, and IL-6 were not significantly affected by the adjuvant use of placebo with Met after 90 days compared with baseline values (Table 5). However, supplementation of GKB extract with Met showed a significant decrease in serum concentrations of hsCRP $(6.2 \pm 4.2$ vs $7.8 \pm 5.0 \mathrm{mg} / \mathrm{L}), \mathrm{TNF}-\alpha$ $(56.5 \pm 34.8$ vs $107.6 \pm 41.9 \mathrm{pg} / \mathrm{mL})$, and IL-6 $(19.8 \pm 12.1$ vs $31.3 \pm 20.5 \mathrm{pg} / \mathrm{mL}$ ) compared with baseline values. Meanwhile, serum TNF- $\alpha$ was found to be significantly lower

Table 5 Changes in the inflammatory markers of metabolic syndrome patients maintained on Met and treated with GKB extract

\begin{tabular}{llllll}
\hline Parameters & \multicolumn{2}{l}{$\begin{array}{l}\text { Met }+ \text { placebo } \\
(\mathbf{n}=\mathbf{1 8})\end{array}$} & & \multicolumn{2}{l}{$\begin{array}{l}\text { Met }+ \text { GKB } \\
(\mathbf{n}=\mathbf{2 2})\end{array}$} \\
\cline { 2 - 3 } \cline { 5 - 6 } & Baseline & $\mathbf{9 0}$ days & & Baseline & $\mathbf{9 0}$ days \\
\hline $\mathrm{hsCRP}(\mathrm{mg} / \mathrm{L})$ & $5.9 \pm 6.2$ & $6.0 \pm 6.1$ & & $7.8 \pm 5.0$ & $6.2 \pm 4.2^{*}$ \\
$\mathrm{TNF}-\alpha(\mathrm{pg} / \mathrm{mL})$ & $117.0 \pm 57.0^{\mathrm{a}}$ & $113.4 \pm 50 . \mathrm{I}^{\mathrm{a}}$ & & $107.6 \pm 41.9^{\mathrm{a}}$ & $56.5 \pm 34.8^{*}, \mathrm{~b}$ \\
$\mathrm{IL}-6(\mathrm{pg} / \mathrm{mL})$ & $27.8 \pm 1.7$ & $32.1 \pm 26.1$ & & $31.3 \pm 20.5$ & $19.8 \pm 12.1^{*}$ \\
\hline
\end{tabular}

Notes: Values are mean \pm SD. GKB: $120 \mathrm{mg}$ GKB extract. Values with nonidentical superscripts ( $a$ and $b$ ) among groups are significantly different (ANOVA, $P<0.05$ ). *Significantly different from baseline in each group (paired $t$-test, $P<0.05$ ).

Abbreviations: ANOVA, analysis of variance; GKB, Ginkgo biloba; hsCRP, high sensitive C-reactive protein; IL-6, interleukin-6; Met, metformin; TNF- $\alpha$, tumor necrosis factor- $\alpha$.
Table 6 Changes in the liver and kidney function markers of metabolic syndrome patients maintained on Met and treated with GKB extract

\begin{tabular}{llllll}
\hline Parameters & \multicolumn{2}{l}{$\begin{array}{l}\text { Met + placebo } \\
(\mathbf{n}=\mathbf{1 8})\end{array}$} & & \multicolumn{2}{l}{$\begin{array}{l}\text { Met }+ \text { GKB } \\
(\mathbf{n}=\mathbf{2 2})\end{array}$} \\
\cline { 2 - 3 } \cline { 6 - 6 } & Baseline & $\mathbf{9 0}$ days & & Baseline & $\mathbf{9 0}$ days \\
\hline GOT (U/L) & $19.1 \pm 6.7$ & $18.3 \pm 5.2$ & & $19.2 \pm 5.7$ & $20.6 \pm 4.1$ \\
GPT (U/L) & $18.5 \pm 7.2$ & $17.4 \pm 5.9$ & & $17.7 \pm 5.9$ & $17.9 \pm 4.9$ \\
ALP (U/L) & $80.2 \pm 23.6$ & $70.8 \pm 20.5$ & & $90.0 \pm 9.1$ & $82.6 \pm 14.5^{*}$ \\
Serum urea (mg/dL) & $25.0 \pm 6.3$ & $26.5 \pm 9.5$ & & $30.1 \pm 8.0$ & $25.4 \pm 7.9 *$ \\
Serum creatinine (mg/L) & $0.64 \pm 0.1$ & $0.73 \pm 0.1 *$ & $0.73 \pm 0.2$ & $0.65 \pm 0.1$ \\
\hline
\end{tabular}

Notes: Values are mean \pm SD. GKB, $120 \mathrm{mg}$ GKB extract. *Significantly different from baseline in each group (paired $t$-test, $P<0.05$ ).

Abbreviations: ALP, alkaline phosphatase; GKB, Ginkgo biloba; GOT, glutamicoxaloacetic transaminase; GPT, glutamic-pyruvic transaminase; Met, metformin.

$(P<0.001)$ than that reported in the placebo-treated group at the end of treatment period (Table 5). All the biochemical analyses regarding the liver and kidney functions indicated no alteration of values after 90 days of GKB treatment (Table 6), except serum ALP and urea where significant decreases were reported in the GKB-treated group compared with baseline values $(P=0.01)$. However, serum creatinine levels were significantly elevated compared with baseline values in the placebo-treated group $(0.73 \pm 0.1 \mathrm{vs} 0.64 \pm 0.1 \mathrm{mg} / \mathrm{dL}$; $P=0.008)$. Table 7 reveals significant increases $(P<0.05)$ in $\mathrm{Hb}$ concentration, Hct, and RBC count in the GKB-treated patients after 90 days compared with baseline values. Meanwhile, placebo treatment did not affect the values of these parameters. The WBC count was not significantly changed in both GKB and placebo groups after 90 days. However, the platelet count was significantly lower $(P=0.002)$ in the placebo-treated group (Table 7). Other safety measurements, including blood pressure, ECG monitoring, and other vital signs were regularly monitored and the baseline values are not remarkably changed during and at the end of the study.

Table 7 Changes in the hematological parameters of metabolic syndrome patients maintained on Met and treated with GKB extract

\begin{tabular}{|c|c|c|c|c|}
\hline \multirow[t]{2}{*}{ Parameters } & \multicolumn{2}{|c|}{$\begin{array}{l}\text { Met + placebo } \\
(\mathrm{n}=18)\end{array}$} & \multicolumn{2}{|c|}{$\begin{array}{l}\text { Met + GKB } \\
(n=22)\end{array}$} \\
\hline & Baseline & 90 days & Baseline & 90 days \\
\hline $\mathrm{Hb}(\mathrm{g} / \mathrm{dL})$ & $12.9 \pm 1.1$ & $13.3 \pm 1.4$ & $12.3 \pm 1.6$ & $14.0 \pm 1.7^{*}$ \\
\hline Hct (\%) & $38.1 \pm 3.5$ & $40.5 \pm 8.5$ & $38.0 \pm 5.5$ & $42.1 \pm 5.8^{*}$ \\
\hline RBC $\left(\times 10^{9}\right.$ cells/L) & $4.6 \pm 0.6$ & $4.7 \pm 0.5$ & $4.8 \pm 0.5$ & $5.2 \pm 0.5^{*}$ \\
\hline WBC $\left(\times 10^{6}\right.$ cells $\left./ \mathrm{L}\right)$ & $8.6 \pm 2.5$ & $7.9 \pm 1.8$ & $8.2 \pm 2.1$ & $7.9 \pm 2.7$ \\
\hline Platelet $\left(\times 10^{9}\right.$ cells $\left./ \mathrm{L}\right)$ & $244 \pm 51$ & $212 \pm 60^{*}$ & $227 \pm 47$ & $235 \pm 57$ \\
\hline
\end{tabular}

Notes: Values are mean \pm SD. GKB, $120 \mathrm{mg}$ GKB extract. *Significantly different from baseline in each group (paired $t$-test, $P<0.05$ ).

Abbreviations: GKB, Ginkgo biloba; Hb, hemoglobin; Hct, hematocrit; Met. metformin; RBC, red blood cell; WBC, white blood cell. 


\section{Discussion}

This is the first pilot clinical study to evaluate the clinical and biochemical outcomes after adjunct use of GKB extract with Met in MTS patients. The results of this randomized doubleblind placebo-controlled study clearly demonstrated that GKB extract (as a single daily dose) for 90 days significantly improved the glycemic status, adiposity, and inflammatory markers (poorly controlled by Met alone) compared with placebo. This finding is a very interesting observation since GKB extract is one of the most widely consumed supplements in Europe and United States. There are many previous reports on GKB antioxidative characteristics and benefits to healthy subjects, ${ }^{20}$ but we attempted to assess its effect on MTS patients with symptoms poorly regulated by Met alone. Generally, people may co-administer GKB extract with other prescribed medications and sometimes may even forget to address this issue to the primary care physicians. Moreover, for chronically administered medications for which clinicians may suggest dose adjustment, it is critical to recognize whether the adjunct use of GKB extract causes changes in patients' responsiveness to the currently used Met. According to the available evidence, it has been already reported that co-administration of $120 \mathrm{mg}$ /day of GKB extract Met did not significantly modify the pharmacokinetic and pharmacodynamic properties of Met. ${ }^{21}$ In the present study, the major limitation was the difficulty in recruiting MTS patients who consume the same Met dose (as daily monotherapy). As the metabolic derangements progress or the patients became non-responsive to Met, another insulin sensitizer may be prescribed as combination therapy. Therefore, the included patients are very heterogeneous and the possibility of evaluating all the doses as monotherapy may be impossible. Accordingly, the outcome of the present study may be ranked as a pilot one. In the present study, treatment with GKB extract improved the glycemic status and insulin sensitivity compared with using a placebo. Additionally, it promoted a significant decrease in $\mathrm{HbAlc}$ levels. In this regard, various studies have shown similar effects, since GKB was capable to enhance response to insulin and improve glycemic control in type 2 diabetes mellitus patients as well as in experimental models of metabolic disorders of carbohydrates and lipids..$^{22,23}$ An interesting observation of the present study was that GKB produced a significant decrease in BMI, WC, and adiposity index compared with placebo. The influence on food intake, within the relatively short period of the study, was excluded since the randomized patients were advised to maintain their commonly followed restricted dietary habits. However, the decreased adiposity might be attributed to the lipolytic effects of GKB biflavones through inhibition of cyclic adenosine monophosphate-phosphodiesterase complex. ${ }^{24}$ In the present study, it has been reported that adjunct use of GKB extract with Met did not alter serum TG levels, which was in tune with a previous report. ${ }^{25}$ However, an interesting observation of GKB use reported in the present study was the significant decrease in adiposity index, which may be involved in decreasing serum LDL-c and TC levels. Our finding seems to be in tune with those observed by Goldberg et $\mathrm{al}^{26}$ and Fayh et al, ${ }^{27}$ who reported a significant decrease in LDL-c, TC, and TG levels associated with the process of weight and adiposity reduction due to GKB extract consumption. Moreover, it has been reported that the reduction in body adiposity resulted in enhanced insulin sensitivity ${ }^{28}$ and the reduction in body adiposity observed in the GKB-treated patients may protect against the effects of disturbed lipid profile on insulin signaling impairment. The association between IL-6, C-reactive protein (CRP), and IR is well characterized as a principal factor of comorbidity in patients with MTS. ${ }^{29}$ Accordingly, the choice of treatment approach that targets these markers seems to be rational. In the current study, we have reported that co-administration of GKB extract with Met attenuates expression of the acute phase protein CRP and the proinflammatory cytokines TNF- $\alpha$ and IL- 6 in MTS patients compared with placebo. Accordingly, our finding suggests that GKB extract has the ability to restore glycemic control and normalize lipid metabolism with a consequent decrease in serum levels of the proinflammatory cytokines. This finding was consistent with previous studies indicating that the administration of GKB decreased inflammation and expression of proinflammatory cytokines such as IL-1 $\beta$, TNF- $\alpha$, and IL- $6 .^{30,31}$ Regarding safety issues, the presented data indicate that GKB extract was well tolerated by the MTS patients. There is no reported incidence of adverse changes in hepatic, renal, and hematopoietic functions. However, GKB extract may significantly improve certain biomarkers of hepatic and renal functions. The current finding was in tune with those reported by others..$^{13,32,33}$ In the present study, inadequate response to the effect of Met monotherapy was reported at baseline and post-treatment in placebo-added approach and no specific mechanism was available yet to explain this phenomenon; however, many observational and prospective trials mentioned this phenomena, some of them attribute it to race differences while others did not show clear comment. ${ }^{34-36}$ In tune with the recent advances in the management of metabolic disorders such as MTS and diabetes mellitus, where monotherapy is not considered as a mainstay approach, many alternative choices for managing metabolic 
derangements are suggested including coadministration of supplements with powerful pleiotropic effects. The present data indicate that adjunct use of GKB extract with Met offers an effective and safe approach for the management of various metabolic abnormalities of MTS. Future studies are warranted to include dose-response evaluation and detailed assessment of the inflammatory status and cover patients with other comorbid conditions.

\section{Study limitations}

The current pilot study is a first attempt to reveal that coadministration of supplement, such as GKB extract, with the routinely used medication in the treatment of MTS has beneficial improvement effects. Although the small sample size might be satisfactory as a first approach, it should be confirmed that clinical trials with larger sample size may confirm or not the present data. Moreover, the limited patient sample did not represent the only study limitation, the limited number of disease markers and/or surrogates may also affect the quality data. However, the strength of this pilot study is the comprehensive approach of the biomarker profile, especially in the context of the expected pleiotropic nature of the evaluated treatment.

\section{Conclusion}

The present study showed that adjuvant use of GKB extract with Met improved significantly the glycemic control, body adiposity, lipid profile, and inflammatory processes in patients with MTS compared with placebo. Taking into consideration that most of the patients with chronic diseases resist complying with treatment protocols, treatment with GKB might be beneficial to avoid the progression of metabolic derangements in those patients.

\section{Acknowledgments}

The data were abstracted from a $\mathrm{PhD}$ thesis submitted by Tavga A Aziz to the College of Medicine, University of Sulaimani. The project was financially supported by the University of Sulaimani (certificate 507/1024). The authors gratefully thank the kind support from the Center of Diabetes and Endocrinology in Sulaimani.

\section{Disclosure}

The authors report no conflicts of interest in this work.

\section{References}

1. Nolan PB, Carrick-Ranson G, Stinear JW, Reading SA, Dalleck LC. Prevalence of metabolic syndrome and metabolic syndrome components in young adults: a pooled analysis. Prev Med Rep. 2017;7:211-215.
2. Francisqueti FV, Nascimento AF, Minatel IO, et al. Metabolic syndrome and inflammation in adipose tissue occur at different times in animals submitted to a high-sugar/fat diet. J Nutr Sci. 2017;6:e41.

3. Gallagher EJ, LeRoith D, Karnieli E. The metabolic syndrome-from insulin resistance to obesity and diabetes. Endocrinol Metab Clin North Am. 2008;37(3):559-579.

4. Hurrle S, Hsu WH. The etiology of oxidative stress in insulin resistance. Biomed J. 2017;40(5):257-262.

5. Motamed N, Rabiee B, Roozafzai F, et al. Metabolic syndrome and cardiovascular risk assessment tools' estimations of 10-year cardiovascular risk: a population-based study. Acta Cardiol. 2017;30:1-8.

6. Swislocki ALM, Siegel D, Jialal I. Pharmacotherapy for the metabolic syndrome. Curr Vas Pharmacol. 2012;10:187-205.

7. Strømgaard K, Vogensen SB, Steet J. Ginkgo. In: Coates PM, Betz JM, Blackman MR, et al, editors. Encyclopedia of Dietary Supplements. 2nd ed. New York: Informa Healthcare; 2010:332-338.

8. Ihl R. Effects of Ginkgo biloba extract EGb $761 \circledR$ in dementia with neuropsychiatric features: review of recently completed randomized, controlled trials. Int J Psychiatry Clin Pract. 2013;17(suppl 1):8-14.

9. Mohanta TK, Tamboli Y, Zubaidha PK. Phytochemical and medicinal importance of Ginkgo biloba L. Nat Prod Res. 2014;28(10):746-752.

10. Mahadevan S, Park Y. Multifaceted therapeutic benefits of Ginkgo biloba L. chemistry, efficacy, safety, and uses. J Food Sci. 2008; 73(1):R14-R19.

11. De Feudis FV, Drieu K. Ginkgo biloba extract (EGb 761) and CNS functions: basic studies and clinical applications. Curr Drug Targets. 2000;1(1):25-58.

12. Zhao Q, Gao C, Cui Z. Ginkgolide A reduces inflammatory response in high-glucose-stimulated human umbilical vein endothelial cells through STAT3-mediated pathway. Int Immunopharmacol. 2015; 25(2):242-248.

13. Yapar K, Çavuşoğlu K, Oruç E, Yalçin E. Protective role of Ginkgo biloba against hepatotoxicity and nephrotoxicity in Uranium-treated mice. J Med Food. 2010;13(1):179-188.

14. Guo RZ, Liu XG, Gao W, et al. Strategy for screening antioxidants in Ginkgo biloba extract by comprehensive two-dimensional ultrahighperformance liquid chromatography. J Chromatogr A. 2015;1422: $147-154$.

15. Xiong XJ, Liu W, Yang XC, et al. Ginkgo biloba extract for essential hypertension: a systemic review. Phytomedicine. 2014;21(10):1131-1136.

16. Shim SH, Kim JM, Choi CY, Kim CY, Park KH. Ginkgo biloba extract and bilberry anthocyanins improve visual function in patients with normal tension glaucoma. J Med Food. 2012;15(9):818-823.

17. Gauthier S, Schlaefke S. Efficacy and tolerability of Ginkgo biloba extract EGb $761 \AA$ in dementia: a systematic review and meta-analysis of randomized placebo-controlled trials. Clin Interv Aging. 2014;9: 2065-2077.

18. Alberti KG, Eckel RH, Grundy SM, et al. Harmonizing the metabolic syndrome: a joint interim statement of the International Diabetes Federation task force on epidemiology and prevention; National heart, lung, and blood institute; American heart association; World heart federation; International atherosclerosis society; and international association for the study of obesity. Circulation. 2009;120(16):1640-1645.

19. Amato MC, Giordano C, Galia M, et al. Visceral Adiposity Index: a reliable indicator of visceral fat function associated with cardiometabolic risk. Diabetes Care. 2010;33(4):920-922.

20. Dai LL, Fan L, Wu HZ, et al. Assessment of a pharmacokinetic and pharmacodynamic interaction between simvastatin and Ginkgo biloba extracts in healthy subjects. Xenobiotica. 2013;43(10):862-867.

21. Kudolo GB, Wanga W, Javorsb M, Blodgettc J. The effect of the ingestion of Ginkgo biloba extract (EGb 761) on the pharmacokinetics of metformin in non-diabetic and type 2 diabetic subjects: a double-blind, placebo-controlled, crossover study. Clin Nutr. 2006;25(4):606-616.

22. Kudolo GB. The effect of 3-month ingestion of Ginkgo biloba extract (EGb 761) on pancreatic beta-cell function in response to glucose loading in individuals with non-insulin dependent diabetes mellitus. J Clin Pharmacol. 2001;41(6):600-611. 
23. Cheng D, Liang B, Li Y. Antihyperglycemic effect of Ginkgo biloba extract in streptozotocin-induced diabetes in rats. Biomed Res Int. 2012;2013:162724.

24. Dell'Agli M, Bosisio E. Biflavones of Ginkgo biloba stimulate lipolysis in 3T3-L1 adipocytes. Planta Med. 2002;68(1):76-79.

25. Llado I, Rodriguez-Cuenca S, Pujol E, et al. Gender effects on adrenergic receptor expression and lipolysis in white adipose tissue of rats. Obes Res. 2002;10(4):296-305.

26. Goldberg Y, Boaz M, Matas Z, Goldberg I, Shargorodsky M. Weight loss induced by nutritional and exercise intervention decreases arterial stiffness in obese subjects. Clin Nutr. 2009;28(1):21-25.

27. Fayh AP, Lopes AL, da Silva AM, Reischak-Oliveira A, Friedman R. Effects of 5\% weight loss through diet or diet plus exercise on cardiovascular parameters of obese: a randomized clinical trial. Eur J Nutr. 2013;52(5):1443-1450.

28. Buettner R, Scholmerich J, Bollheimer LC. High-fat diets: modeling the metabolic disorders of human obesity in rodents. Obesity. 2007; 15(4):798-808.

29. Siegel G, Ermilov E, Knes O, Rodríguez M. Combined lowering of low grade systemic inflammation and insulin resistance in metabolic syndrome patients treated with Ginkgo biloba. Atherosclerosis. 2014; 237(2):584-588.

30. Chen CC, Chiang AN, Liu HN, Chang YT. EGb-761 prevents ultraviolet B-induced photoaging via inactivation of mitogen-activated protein kinases and pro-inflammatory cytokine expression. J Dermatol Sci. 2014;75:55-62.
31. Yin D, Tao J, Lee DD, et al. Recovery of islet $\beta$-cell function in streptozotocin-induced diabetic mice: an indirect role for the spleen. Diabetes. 2006;55(12):3256-3263.

32. Koo JW, Chang MY, Yun SC, et al. The efficacy and safety of systemic injection of Ginkgo biloba extract, EGb761, in idiopathic sudden sensorineural hearing loss: a randomized placebo-controlled clinical trial. Eur Arch Otorhinolaryngol. 2016;273(9):2433-2441.

33. Gavrilova SI, Preuss UW, Wong JW, et al. Efficacy and safety of Ginkgo biloba extract EGb 761 in mild cognitive impairment with neuropsychiatric symptoms: a randomized, placebo-controlled, double-blind, multi-center trial. Int J Geriatr Psychiatry. 2014;29(10):1087-1095.

34. Williams LK, Padhukasahasram B, Ahmedani BK, et al. Differing effects of metformin on glycemic control by race-ethnicity. J Clin Endocrinol Metab. 2014;99(9):3160-3168.

35. Mendez-del Villar M, Martinez-Abundis E, Preciado-Marquez RO, Gonzalez-Ortiz M. Effect of diacerein as an add-on to metformin in patients with type 2 diabetes mellitus and inadequate glycemic control. Arch Endocrinol Metab. 2017;61(2):188-192.

36. Liu H, Hu Y, Li F, Liu B, Su X, Ma J. Blood glucagon levels predict the hemoglobin A1c response to saxagliptin in patients with type 2 diabetes inadequately controlled with metformin. Diabetes Ther. 2016; 7(4):743-753.
Therapeutics and Clinical Risk Management

\section{Publish your work in this journal}

Therapeutics and Clinical Risk Management is an international, peerreviewed journal of clinical therapeutics and risk management, focusing on concise rapid reporting of clinical studies in all therapeutic areas, outcomes, safety, and programs for the effective, safe, and sustained use of medicines. This journal is indexed on PubMed Central, CAS,

\section{Dovepress}

EMBase, Scopus and the Elsevier Bibliographic databases. The manuscript management system is completely online and includes a very quick and fair peer-review system, which is all easy to use. Visit http://www.dovepress.com/testimonials.php to read real quotes from published authors. 